\title{
Physically Transcendent Awareness: A Comparison of the Phenomenology of Consciousness Before Birth and After Death
}

\author{
Jenny Wade, Ph.D. \\ Institute of Transpersonal Psychology, Palo Alto, CA
}

\begin{abstract}
Veridical evidence of a physically transcendent source of consciousness comes from both extremes of the life span when central nervous system functioning is compromised, suggesting that some form of personhood can exist independently of known cellular processes associated with the body. In pre- and perinatal accounts, veridical memories have surfaced of events in the first two trimesters, long before the central nervous system is fully functional, continuing through the third trimester, when measurable brain activity begins, until just after birth. In the empirically verifiable out-of-body phase of near-death experience (NDE) accounts, a source of consciousness has been shown to record events when measurable metabolic processes, including brain activity, have ceased altogether. These two states have similar phenomenologies, suggesting that a physically transcendent source representing individual consciousness predates physical life at the moment of conception and survives it after death, and that its maturity and functioning do not directly reflect the level of central nervous system functioning in the body.
\end{abstract}

Evidence for a physically transcendent source of consciousness comes from the extremes of the life span when central nervous system functioning is compromised: before birth, when neurological processes are demonstrably immature, and after death, when the brain has ceased measurable activity. Increasing evidence indicates that, in both prenatal and postmortem states, some form of mind is present and functioning when the brain is not. These independent bodies

Jenny Wade, Ph.D., is on the core faculty of the Institute of Transpersonal Psychology in Palo Alto, CA. Reprint requests should be addressed to Dr. Wade at P.O. Box 571, Ross, CA 94957. 
of research provide verifiable evidence of consciousness that transcends the physical limitations of the body as we know it. Moreover, prenatal and near-death awareness share common characteristics. This paper discusses the veridical evidence for a transcendent source of consciousness before birth and after death, and the extent to which those states resemble each other.

First, it is necessary to understand the role of memory and its importance in the prenatal and near-death studies. The data, for obvious reasons, do not come from fetuses or dead people, but from living subjects who recollect events that occurred when their bodies were in those states. Memory is, therefore, critical to the evidence I will be considering. It is also an integral part of awareness, inseparable from the phenomena of consciousness. Cohering moment-to-moment experience, memory is the foundation that creates continuity of mind and the ongoing sense of self (Eccles, 1989; Penfield, 1975; Restak, 1984). Without memory, we would not know who we were when we woke up or how to relate ourselves to the world. Our sense of self in large part comes from our recollecting and stringing together a set of memories that we recognize as being uniquely our own.

Unfortunately, the phenomenon of memory is not well understood. The physiological basis for memory has been debated since the 1940s. Today there are three schools of memory theory that can be grouped according to where they locate memory in the body: local, in identifiable structures; nonlocal, associated with identifiable body structures, but not necessarily reducible to them; and completely nonphysical or transcendent. Each school is supported by a wealth of empirical data, but none of it is conclusive (Gregory, 1987).

Originally researchers such as Donald Hebb and Wilder Penfield supported localized models: particular memories are stored in, and transmitted by, particular neuronal circuits (Bloom, Lazerson, and Hofstadter, 1985; Galluscio, 1990; Gregory, 1987). In these theories, consciousness is a function of the central nervous system, a mechanistic view consistent with the Western medical tradition of specialized physiological parts with distinct functions. Localized models remain current (Dennett, 1991), but they cannot account for prenatal and near-death memories when central nervous system processing is absent.

Nonlocalized models are represented by two mainstream theories. One is a holographic model of the central nervous system. First introduced by Karl Lashley's empirical research in the 1940s, this non- 
localized model represents information storage as "a molar property of the mass of cortical cells, a 'field' rather than a 'point"' (Gregory, 1987 , p. 458). The theoretical rationale for such findings lagged until the advent of holography. Karl Pribram (1971, 1991) synthesized Lashley's and others' research into a holographic model of the brain, considered to be a revolutionary advance in neurological theory. Since this nonlocalized theory still associates memory with central nervous system functioning, it may not account for evidence of consciousness when measurable brain activity is absent.

The other current nonlocalized model depends upon biochemical transmitters. One prominent theory contends that ribonucleic acid (RNA), a compound in the nuclei of all living cells, not only conveys genetic information but transmits memory as well (Dossey, 1989; Buchheimer, 1987; Rossi, 1990). RNA's ubiquitous presence means that memory is stored all over the body, not merely in the central nervous system. Candace Pert's investigations of neuropeptides have bolstered interest in the biochemical transmitter argument (Achterberg, 1985, 1994; Pert, Ruff, Weber, and Herkenham, 1985; Rossi, 1990). This theory can account for somatic memories of trauma in fetal life before the central nervous system is completely developed and for detailed information regarding the state of the organism, such as the accurate reproduction of birth positioning (Cheek, 1974, 1975; Janov, 1970, 1983) and "lost" instinctive behaviors, such as the Babinski reflex (Grof and Bennett, 1990; Raikov, 1980). To date, cellular chemistry theories have tended not to address near-death phenomena. But in any case, it is difficult to see how impressions retained by nonspecialized cells could account for the extrasensory perceptions and complex ideation present in near-death and prenatal records.

Finally, some eminent medical researchers, including Penfield toward the end of his career (1975) and John Eccles (1989), incline to a model unfettered by material limitations, an idea ventured by Nobel laureate Charles Sherrington in the 1930s but whose origins go back to Platonic thought. They suggest that the source of memory may have a temporary physical expression in the body, such as in the brain, RNA, or neuropeptides, during embodied life that does not reflect its physically transcendent nature (Grof, 1985; Verny and Kelly, 1982). Respected scientists, such as Nobel laureate Brian Josephson, believe that these phenomena will be confirmed scientifically (Josephson and Pallikari-Viras, 1991; Radin and Nelson, 1989). Such a theory is the only one that can account fully for many pre- 
natal and near-death findings, and I suggest that those findings may be the beginnings of the scientific confirmation Josephson is seeking.

Taking the most conservative stance, I have limited this paper to reports of veridical memories that occurred when the central nervous system was nonfunctional, or at best, was severely compromised. The absence of measurable brain activity is presumed in many of the near-death records, but it has not always been verified; that is, not everyone pronounced dead was connected to an electroencephalograph (EEG). The pre- and perinatal records are more complex because they occur over a period when the central nervous system is developing and neurological functioning is increasingly stronger. Of course, in both instances brain functioning may not be entirely absent; it is always possible that some level of neurological processing is occurring at levels undetectable by current technologies. I have further narrowed the data gathered from near-death and prenatal studies to complex thought, such as the description of events, a level of functioning that cannot easily be accounted for by bodily states or the transmission of information at the cellular level. Finally, this paper only treats veridical information, that is, reports independently verified by third parties: the portions of prenatal and near-death records that can be validated by medical personnel, relatives, and others.

Starting with the pre- and perinatal evidence, it is important to note the physiological limitations of brain functioning during fetal life and the perinatal period, here defined as the first 72 hours after birth. Fetal brain cell division is complete as early as 16-20 weeks after gestation. Thus humans are born with all the brain cells they will ever have during life. But the neonate brain is only one-fifth the size of the adult brain because it lacks the axons and dendrites that constitute the synaptic networks connecting the neural cell bodies (Greenough, 1987; Restak, 1986). Higher brain function-for our purposes, conceptual thought-is believed to depend upon the formation of these billions of intercellular connections. But virtually all of them develop after birth; they are not present or functioning during the period I am discussing.

Furthermore, measurable brain activity, in the form of bilaterally synchronous fetal EEG activity, does not begin until the third trimester, 28-32 weeks after conception (Anand and Hickey, 1987; Spehlmann, 1981). After 30 weeks, distinctive types of fetal consciousness, such as waking and sleeping, including even rapid-eyemovement (REM) sleep, can be discerned with monitors. Without 
substantial cortical connections and myelinization, however, the ability for thought and memory is technically quite limited.

Even at birth, neonatal neurological capability is substantially different from the consciousness of adults. Newborns exhibit great alertness for a few hours after birth, a marked contrast to the weak, fluctuating, dreamy state that characterizes the first weeks of life (Gregory, 1987). During these early weeks, even when the newborn's eyes are open, he or she is not awake as we know it. EEG patterns indicate that open-eyed neonates may be experiencing any of six distinct types of consciousness, only one of which is sufficiently active and alert to resemble the child's or adult's experience of being awake (Bower, 1977).

Having established the neurological limits of pre- and perinatal consciousness, I turn now to the evidence of veridical memories of events occurring during that time. Perhaps the least disputed and most disarming are the memories spontaneously expressed by very young children. This is a new area of research in the West, where children's recall of early events has tended to be dismissed as fantasy. Toddlers' stories generally appear between the ages of 2 and 3 when they start talking, and seem to be forgotten by about age 5 (Chamberlain, 1988a). Completely voluntary accounts seldom come to the attention of researchers, and are not very detailed, as would be expected. They also seem to be confined to later events around the birth. Jason, a $3^{1 / 2} 2^{-y e a r-o l d ~ b o y ~ r i d i n g ~ h o m e ~ i n ~ t h e ~ c a r, ~ s u r p r i s e d ~ h i s ~}$ mother by saying that he remembered being born, that he had heard her crying and was doing everything he could to get out.

It was "tight," he felt "wet," and felt something around his neck and throat. In addition something hurt his head and he remembered his face had been "scratched up."

Jason's mother said she had "never talked to him about the birth, never," but the facts were correct. The umbilical cord was wrapped around his neck, he was monitored via an electrode in his scalp, and was pulled out by forceps. The photo taken by the hospital shows scratches on his face. (Chamberlain, 1988a, p. 103)

Accounts elicited from children have proven reliable as well. A girl 3 years, 9 months old remembered an event that had been kept secret even from her family (Chamberlain, 1988a). Cathy, the assistant midwife, had been left alone with the baby just after the birth. When the infant began to cry, Cathy instinctively offered her own breast for the baby to suckle. By the time the mother returned, the baby was asleep. Cathy felt guilty about being the first to nurse the child, 
so she said nothing about it. Almost four years later as Cathy was babysitting a group that included this little girl, she asked if the child remembered being born. The girl not only proceeded to give an accurate account of who was present and their roles during labor and delivery, but, apparently sensitive to Cathy's unspoken guilt, she "leaned up close and whispered in a confidential tone, You held me and gave me titty when I cried and Mommy wasn't there" (Chamberlain, 1988a, p. 104).

Most of the prenatal data are recollections older subjects produce during therapeutic or experimental conditions. Prenatal memories tend to emerge during altered states, although they appear to be elicited by any work with the deeper layers of the psyche, including traditional psychoanalysis; Rolfing, accupressure, and other bodywork; hypnosis; rebirthing and other kinds of breathwork; and sensory isolation. Such memories surface in the same way as recollections from childhood, by bringing core issues into the open where they can be dealt with consciously.

First, these early impressions seem to involve an out-of-body vantage point. A close examination of published regression transcripts from older subjects reveals evidence of two intermittent streams of awareness, one assuming a vantage point within the uterus, the other one located outside the baby's body, and apparently outside the mother's body as well. Switches in vantage point occur in virtually all records. Very young children do not seem bothered by the dual vantage point, but older subjects may express puzzlement even under hypnosis, as these four accounts illustrate.

At times I feel like I'm somewhere in the room witnessing what is going on, and at other times I am the child and seeing it from that point of view ... I wonder how come I can see around behind him? ...

It's like standing there in the same room. Sometimes I can feel it and sometimes I'm watching.

It's like flashing both. It's like I am somebody else looking at what's happening. Am I making this up? I don't think I am, but I hesitate to say what I'm actually seeing . . . .

I keep looking through the nursery window. It's weird. I can't be on both sides of the window? I'm looking at the baby; it's me. (Chamberlain, 1988a, pp. 187-188) 
The least ambiguous evidence supporting a distinct transcendent perspective comes from very early in gestation, before measurable brain activity has started. Regression therapists believe the events most likely to be impressed in memory are those that are highly emotional for the subject: the moment of conception, the discovery of the pregnancy, the first communication about the pregnancy, and the birth (TenDam, 1990). Of course, such times may also be highly emotional for the mother, whose hormonal changes would be affecting the fetus in a concrete way, perhaps creating a physiological mode of information transmission. Regression subjects, however, have accurately reported incidents long before any significant brain development had occurred, in some cases before the embryonic body was even formed.

For example, veridical memories extend to events surrounding conception (Chamberlain, 1990; Grof and Bennett, 1990). Stanislav Grof, David Chamberlain, and David Cheek have verified even the earliest experiences recounted against information provided by the mother, relatives, obstetricians, and medical records. Often accounts contain accurate reports of complex impressions, such as abstruse medical conditions or procedures few lay people know about (Chamberlain, 1990; Grof, 1985; Laing, 1982). In one case, memories were dated by having naive subjects describe their relative head-to-shoulders size as an index of fetal age (Van Husen, 1988). The following is a typical example of a conception memory.

Ingrid remembered her mother and father making love on a couch in Germany, before they were married. The doorbell rang to announce that Grandmother and Aunt had come back from shopping when they weren't supposed to. The encounter sent shockwaves through all present. Ingrid says, "Mother was beside herself. She knew she got pregnant. She was ashamed. She didn't want to do it in the first place ..." (Chamberlain, 1990, p. 181)

Most published reports describe somewhat later events, especially attempted abortions. For obvious reasons, these kinds of stories had virtually never been communicated to the subjects; verification was obtained from the mothers after the material was produced by regression. The first account below occurred about six months into the pregnancy; the second, probably during the first trimester.

[Subject]: It's before I'm born. My father is shouting, 'I'm going to kill you." (A few seconds later, [Subject] began screaming. She pulled her legs up to her chest as though trying to get away from something very frightening.). . . I saw that button hook coming up at 
me. I knew my mother was trying to get me out.

[Therapist]: Then what happened?

[Subject]: Nothing happened—only a little bleeding. (Cheek, 1992, p. 130)

I was hardly formed and my mom is using some kind of remedy to wash me away. It feels real hot. . . .I know she is trying to get me out of there. I'm just a little blob. I don't know how I know, but I know. My aunt seems to be giving my mom directions. I can hear her voice and another woman in the background. She is not supposed to get pregnant. . . . It didn't work either. It had a . . .vile strong smell. I can see where I was too; I was way up there, just teeny. (Chamberlain, 1990, p. 179)

Regression records also demonstrate paranormal knowledge of the unspoken thoughts of others, especially the parents. Subjects have recalled the mother's ambivalence, happiness, or resentment over her pregnancy. In many cases, these experiences and impressions have been verified against information provided by the mother, relatives, obstetricians, and medical records (for example, Grof and Bennett, 1990). These telepathic impressions from regression reports are substantiated by independent research involving direct fetal observation (for example, Lieberman, 1963; Veldman, 1982). Arguably any information from the mother might be transmitted through some physiological process presently unknown to science, but it is difficult to see how verbatim recollections of events outside the womb, such as the father's shouting and the women's discussion of abortion methods above, could be transferred through undifferentiated cellular tissue.

The extent to which meaning is made of these recollections relies somewhat on verbal ability, a quality mature subjects bring to any regression. Are they merely giving words to a feeling impression? Or, since research has shown that infants retain auditory stimuli that were repeated during their gestation, are the subjects retrieving memories of actual words spoken? Aural memories are not possible until the midterm, when the fetal ear, the cochlear nerve, and its associated neural networks create the ability to hear (Tomatis, 1987). Myelination of the cochlear nerve is complete at 22 weeks, spreading into the brain so that the temporal lobe is completely myelinated and functioning at birth. However, researchers do not claim that language is understood, but rather that familiar patterns of intonation, rhythm, and pitch are recognized (Blum, 1993; Tronick and Adamson, 1980). Yet regressed subjects can repeat conversations overheard once, as the examples above demonstrate. Are meaningless sounds retained by the fetus decoded into language by a more mature subject 
under hypnosis? That seems doubtful, given the timing of some of these accounts, unless aural memories can be retained in undifferentiated tissue like RNA or other biochemical transmitters.

To check the veracity of histories produced during hypnosis, Chamberlain elicited birth accounts from ten mother-and-child pairs in separate regressions, and then compared the records (1988a). The children, with an average age of 16 years, who had no conscious recollection of their birth, produced remarkably detailed accounts that dovetailed on major points with their mothers'. Narratives included accurate reportage of the time of day, locale, persons present, instruments used, position of delivery, and the medical personnel during the birth. Reports extended over the next several days, including correct feeding sequences of water, formula, and breast feedings; room layouts; details of discharge; and arrival at home. Chamberlain noted minor errors and disagreements but stated that serious, direct contradictions were quite rare. The results cannot be explained by the mother's memories being passed along to the child because the child's recollections often contained information unknown to the mother, or material she would not have divulged. Where differences occurred, usually the child's account was verified by doctors and nurses as the correct one. Fantasies were fairly easy to spot, and occurred in only one of the ten records, and in that case, in only one phase of the report. The following excerpt from one pair shows the parallels.

\section{Mother:}

They sort of put her on my stomach but they're still holding onto her ... lots of blood and white stuff. She's crying. I can see the umbilical cord. My hands are fastened down because I can't reach out and touch her. I would like them to move her, wrap her up. I'm talking to the doctors .... . I think they had a white cap over my hair. They finally undo my hands and the nurse brings her over on my left side. But she doesn't hold her close enough so I can touch her. I really feel frustrated. I do say "Hi!" to her ... . . I talk to the doctor about her weight.

Child:

They put me on her stomach, sort of dumped me on her. He's talking to my mom. Everything seems to be okay and she's all right. . . . I feel bigger and heavier. I can see her but I'm not by her. Her hair is wrapped up, like in curlers or something. She looks tired, sweaty. Nobody's talking to me. They're talking about me, I think, but not to me. They act like they know I'm there but like $I$ don't know I'm there. ... The nurse kind of wiped me. Then they brought me over next to my mother. She wasn't crying but something like that. She's 
the first one that talked to me. She said "Hi!" Nobody else seemed to think that I was really there. Then she talked to the doctor a little bit and they took me away again. (Chamberlain, 1988b, p. 21)

Evidence strongly suggestive of a physically transcendent or extrasensory source of perception comes from veridical visual images impossible to obtain from inside the womb. Detailed visual descriptions demonstrate an out-of-body vantage point from which the fetus can see things their eyes could not see from inside the mother's body. Moreover, fetal eyes are not fully functional, as the eyelids are fused until the $26^{\text {th }}$ week (Chamberlain, 1994).

Mother is sitting on a couch knitting something. Daddy comes in and is asking why she is knitting something for a girl. Mother says, "It's a girl. I know it's a girl. It has to be a girl." ... She has on a green plaid dress. I can't see any other color. I think it is dark."

[The mother] exclaimed, "I had a green and black plaid dress on and I can remember when that was! I had just begun feeling Debbie kicking. It was in April. . . . I gave that dress away right after my pregnancy. I would have been almost five months along." (Cheek, 1986, pp. 106-107)

My client Loretta, while still in the womb, remembered her mother standing on the deck of a boat, holding tightly to a railing, tense, and trying to steady herself. "She's looking at an island. There are other people looking over the water, listening to someone tell them where they are going, explaining to them about the island. My father is standing by my mother, worried about her. He wants to know if she is all right. The rocking of the boat is making her sick. She sat down and is rubbing her stomach."

Loretta's mother and father were surprised to hear this story coming out of the third trimester of pregnancy. They said she had correctly reported their outing on a sightseeing boat but said they had never told her about it. (Chamberlain, 1990, pp. 178)

These visual reports clearly represent extrasensory perception, since no part of the fetal body is in a position to capture visual images, according to our present understanding of anatomy. Even if it were, the fetal eyes are unable to process images, since optical functioning is extremely poor as late as birth. Newborns have difficulty focusing, fixating on stationery and moving objects, and even converging both eyes on a single target (Flavell, 1985). Contrast sensitivity is quite poor, and visual acuity is perhaps only $20 / 600$. Thus, visual memories even at birth confound the notion that consciousness resides in the central nervous system. Yet extremely detailed reports, 
including descriptions of the people present, what they were wearing, and procedures and instruments used, have been collected and verified by third parties in a number of studies (Chamberlain, 1981, 1987, 1988a, b; Cheek, 1986, 1992).

One of the strongest arguments for a materially transcendent source of awareness is the documentation of veridical self-aware, visual memories of birth. These impressions occur when sight is not possible, either because the baby's eyes are shut and its face is pressed against the walls of the birth canal, or, when the head is free, because neonatal optical processing is extremely limited, as noted above. Birth records are characterized by a strong sense of self-awareness and ideation "startlingly mature at times, including insights, decisions, compassion for the mother, curiosity about the father, as part of the action at the time, not added later" (Chamberlain, 1987, p. 84; emphasis added).

I do not refer to the obvious maturity of adult subjects using mature language; I refer to the maturity of the perceptions and thoughts moving through the infant mind at the time. This unexpected maturity is seen in expressions of compassion and love, moral anguish, clear insights about people and their relationships, problem solving and decision making, critical commentary on how birth is handled, and comprehension of what things mean. (Chamberlain, 1988b, p. 20)

In one extraordinary account, a regressed subject named Deborah not only felt more intelligent and insightful than the hospital staff, but described herself prior to birth as being a mind, not embodied (Chamberlain, 1988a).

Then all of a sudden there was this yellow room and these people. That's when I was beginning to figure out what was going on. Not very happy about it. . . . I didn't realize right off that I could make noises [cry]-that seemed to just kind of happen. . . . Starting to breathe was pretty strange, too. I had never done anything like that before ....

The breathing was just in bursts at first, every time I made a noise. Then I noticed every time I was doing it I was doing it in between the noises, so I was thinking about that, too. It kind of distracted me from being mad because I was concentrating on what was going on inside me. Listening to the way it sounded. Feeling the air go in and out. Making it go faster and slower-that was kind of a neat idea. I thought as long as I had to be in this place, I might as well have something like noise and air. Kind of gave me something to do....

I felt I knew a lot-I really did. I thought I was pretty intelligent. 
I never thought about being a person, just a mind. I thought I was an intelligent mind. And so when the situation [of being born] was forced on me, I didn't like it too much.

I saw all these people acting real crazy. That's when I thought I really had a more intelligent mind, because I knew what the situation was with me, and they didn't seem to.

They seemed to ignore me. They were doing things to me-to the outside of me. But they acted like that's all there was. . . (Chamberlain, 1988a, pp. 155-157)

Deborah's identification of herself as a mind-and all the direct records showing two intermittent sources of consciousness-are corroborated by the independent research of Helen Wambach (1981). She regressed more than 750 people and then had them describe their experience of fetal life. Eighty-nine percent of her subjects reported having two separate, simultaneous sources of awareness. They did not identify with the growing fetus or its stream of consciousness, although they accepted that the fetus was "theirs." Instead, they identified themselves with a nonphysical source of consciousness, and tended not to become involved with "their fetus" until six months after conception. In fact many were extremely reluctant to join "their consciousness" with the fetus. Wambach's subjects characterized themselves as disembodied minds hovering around the fetus and mother, being "in and out" of the fetus and having a telepathic knowledge of the mother's emotions throughout pregnancy and birth.

One-third of Wambach's subjects said they did not come into the fetus or join their consciousness with that of the fetus until just before or during birth; 12 percent stated they attached to the fetus about the beginning of the third trimester, which interestingly is when brain activity is first observed; and only 11 percent reported prior attachment to the fetus (1981). The rest joined within a day or two after birth. Subjects ascribed their reluctance to join with the fetus to negative feelings about being born. Approximately 68 percent expressed antipathy and anxiety about being embodied. Their attitude was resigned toward physical life as an unpleasant duty they had to perform in response to an unidentified imperative.

Other researchers agree that awareness predates conception, hovers above and around the mother during pregnancy, vacillates between a fetal and an external vantage point, frequently does not "permanently" enter the baby until after birth, and then often quite reluctantly (Chamberlain, 1990; Gabriel and Gabriel, 1992; Whitton and Fischer, 1986). 
From these accounts, it is plain that the phenomenology of this physically transcendent source of consciousness is somewhat different from "normal" consciousness. Spatial orientation indeed seems to conform to the familiar three-dimensional, Newtonian convention, and events are reported sequentially as they unfold. However, the sequence of discrete events is often confused, and subjects report a sense of timelessness (Chamberlain, 1988b; Gabriel and Gabriel, 1992; Verny and Kelly, 1982). Researchers postulate variously that the sense of timelessness may be inherent in fetal and infant consciousness before linearity is constructed (Gabriel and Gabriel, 1992) or that it may be inherent in the altered state accessing such memories (Tart, 1972, 1983). The portions of records in the physically-transcendent voice, describing perception from the external vantage point, seem rather devoid of emotion, even when the subject is viewing highly evocative events; when, however, the vantage point shifts to inside the fetal body, emotions are strong.

Taking all the data together, the phenomenology of the nonphysical source of prenatal consciousness includes the following characteristics. The attitude toward life seems to be that it is necessary but unpleasant, and that there is an obligation to be born incarnate. Self boundaries are real, but not physical except as related to the fetal body. The transcendental self has no body but is spatially located in, and limited to, an area around the mother's body; it includes the fetal body, brain, and emerging consciousness, though this is sometimes viewed as an alien or shadow part of the self. The perception of temporality is of a timeless present. The concept of others is fully mature, seeing others as human beings in their own right, and highly insightful, with telepathic knowledge of others' thoughts and feelings without their verbalization. The pre- and perinatal transcendent self seems to record and process information about people without emotional loading or neurotic projection. The locus of control is external. The level of abstraction appears to be Newtonian, with formal operations observing spatial and temporal boundaries of the stream of consciousness, even though the source of consciousness operates outside some of these boundaries. Options for action seem to include being born or self-aborting, and the correct option to be born despite repugnance.

To summarize the prenatal data, the regression research suggests that a transcendent source of consciousness exists before birth. While the brain lacks measurable coordinated activity until the third trimester, the transcendent source with its mature, unchanging aware- 
ness may be present even before conception. It seems to be spatially and temporally limited to an area immediately around the fetal body or the mother from conception up to an extreme limit of two days after birth. At some point during the pregnancy or perinatal period, the transcendent source becomes "stuck" to its body with less freedom to dissociate its quasi-independent selfhood from that of the fetus. For the majority of people, this joining coincides with the period when measurable brain wave activity commences. The fact that neonates exhibit great alertness for the first few hours after birth, in contrast to the vague, dreamy state that characterizes the first few weeks of life, suggests that perinatal consciousness, as narrowly defined here, may represent a unique phenomenon when the transcendent source is still relatively accessible (Wade, 1996).

Turning now to the near-death literature, I must first address the definition of death, popularly regarded as a single moment when the animating energy leaves the body. Medically, however, death is believed to be a process without a clear ending or beginning. Cellular death occurs at different rates, and although different signs, such as cessation of breathing and reflex actions or flat EEGs, are considered diagnostic of death, people have recovered after having exhibited all of these symptoms (Baden and Hennessee, 1989; Carr, 1993; Milbourne, 1979). According to our current ability to measure consciousness, a flat EEG technically means brain activity has ceased. Yet people who have been certified "brain dead" have come back to life, reporting conscious experiences during that time (Moody, 1975, 1977; Ring, 1980, 1984; Sabom, 1982). Such recoveries have altered our understanding of death, leading some medical scientists to maintain that survivors, by definition, were never "really" dead in the first place; brain activity, therefore, must not have stopped despite evidence to the contrary. The only remaining medical definition of death seems to be irreversible biological deterioration, which can be known only by its permanence (Baden and Hennessee, 1989; Milbourne, 1979). Therefore, despite meeting current medical definitions for death, the phenomena discussed here cannot be unequivocally considered postmortem events.

As mentioned earlier, the only portion of the near-death records treated in this paper concerns evidence of physically transcendent experiences in the familiar reality that can be independently verified by third parties. This phase occurs early in the near-death experience (NDE). At some point during the dying process, though its relation in time to EEG cessation or any other metabolic measurement of 
death is presently unknown, the sense of subjective consciousness leaves the body, though it is experienced as a continuation of the same self (Greyson, 1985; Moody, 1975, 1977; Ring, 1980, 1984). The dying person's perspective moves upward so that it is looking down at the body. The shift may be accompanied by a loud noise and the sensation of a dark void. There seems to be no source of awareness left in the body. Since continuity of self accompanies the shift to a disembodied view, many survivors have reported that they at first did not realize that they were dead until someone living, such as medical staff, family, emergency workers, or passers-by, announced that fact or it was otherwise drawn to their attention.

Affect is present, but often not particularly strong. The dying individual initially enjoys an extremely positive emotional experience (Moody, 1975, 1977; Ring, 1980, 1984). Fear and pain associated with the body and the struggle to live vanish. Subjects commonly note a sense of expansiveness, peace, relief, and well-being at being out of the body, even knowing they are dead, though some few are anxious to return to the body. Feelings toward the body tend to include indifference or repugnance, but not remorse. Many express disgust that they were housed in such coarse material, parallel to the reluctance expressed by Wambach's subjects toward incarnation. Subjects are bemused by resuscitation efforts, often wishing them discontinued. Some attempt to convey a message of comfort to the grieving to let them know they are all right.

Survivors have variously reported lingering in the immediate vicinity of their bodies or finding themselves in more remote surroundings, such as another part of the hospital or with loved ones at home (Moody, 1975; Ring, 1980, 1984). To illustrate a case of immediate proximity even when the body was moved, an 8-year-old boy fell from a bridge, hitting his head on a rock in the water below (Morse and Perry, 1990). He had stopped breathing and was without a pulse when a police officer pulled him from the deep water where he had been submerged for at least five minutes. The policeman, who performed cardiopulmonary resuscitation for 30 minutes until a hospital helicopter arrived, declared the boy dead at the scene. The boy was resuscitated at the hospital, however, but did not regain consciousness until two days later. He then proceeded to recount in detail the rescue effort, naming the police officer who rescued him, stating how long it took for the helicopter to arrive, and describing the resuscitation procedures performed. The boy said he had watched all these events from outside his body. To illustrate the experiencing of events 
remote from the body's immediate surroundings, one amusing case comes from a woman whose source of awareness left the room where her body was being resuscitated to observe her brother-in-law in the hospital lobby talking to a business acquaintance he had met there by chance (Moody and Perry, 1988).

"Well, I was going out of town on a business trip," said the brotherin-law. "But it looks like June is going to kick the bucket, so I better stay around and be a pallbearer."

A few days later when she was recovering, the brother-in-law came to visit. She told him that she was in the room as he spoke to his friend, and erased any doubt by saying, "Next time I die, you go off on your business trip because I'll be just fine." (Moody and Perry, 1988, p. 19)

Near-death out-of-body consciousness functions in the same spatiotemporal realm as ordinary consciousness, in which solids occupy three-dimensional space and persist in time, but it possesses abilities not associated with a material body (Carr, 1993; Zaleski, 1987). This source of awareness can pass through solid objects and/or "think" itself to another location without engaging in locomotion or sensing passage through three-dimensional space (Greyson, 1985; Moody, 1975, 1977; Ring, 1980, 1984; Zaleski, 1987). Places may be experienced in a directional sequence but possess an unclear expanse, or have an indeterminate distance between them (Carr, 1993). Temporality also appears to be distorted. Many survivors say time in this state does not exist, although they are able to assign a sequential order to their experiences, even if they have no sense of duration. Some feel that time around them is slowed down or sped up.

Although this out-of-body self can see and hear the living for prolonged periods, the living in turn often cannot sense it at all, or only quite briefly (Longman, Lindstrom, and Clark, 1988). Survivors of NDEs do not agree on a physical form for this self, except its intangibility. Many are unaware that they have any somatic presence, while others describe an ephemeral or "energy" body that may resemble a human form or a sphere (Carr, 1993; Zaleski, 1987). Hans TenDam (1990, p. 173) suggested that these forms are "psychoplastic," that is, shaped by the subject's ideas of how the self is experienced. Sensations of weight and movement are virtually nonexistent (Carr, 1993; Zaleski, 1987). Survivors' sensory impressions are mostly limited to sight and hearing, although a minority report some ability to touch and smell (Blackmore, 1993; Longman, Lindstrom, and Clark, 1988; Ring, 1980, 1984). 
Mentation is alert, and perception vivid, combining to form a hyperlucidity (Moody, 1975, 1977; Ring, 1980, 1984). The deceased exhibit the same detailed and accurate perceptions as do prenatal subjects, similarly verified by family members, rescue workers, onlookers, and medical personnel. The near-death literature abounds with veridical accounts in which subjects accurately describe complicated and, often from their view, incomprehensible resuscitation procedures (Morse and Perry, 1990). For instance, Michael Sabom (1982) compared accounts from 32 naive survivors of near-death cardiac arrests with a control group of 25 medically sophisticated people who had not had an NDE, asking them to describe what they thought occurred when medical teams attempt to restart a heart. All of the naive subjects gave correct descriptions of the procedure; only two of the 25 knowledgeable subjects did so.

Veridical examples of psi phenomena during the out-of-body phase, such as the telepathic transfer of information, are plentiful (for example, Morse and Perry, 1992; Ring, 1984). Telepathic abilities resemble the pre- and perinatal ability to read thoughts. For example, a cardiologist rear-ended a car on his way to work (Moody and Perry, 1988). Throughout the day, including the time he spent resuscitating a heart-attack victim, he was preoccupied with worry that the car's occupants might sue him. The patient he treated survived, and the next day,

he told the doctor how the instruments looked, and even in what order they were used. He described the colors of the equipment, shapes and even settings of dials on the machines.

But what finally convinced this young cardiologist that the man's experience was genuine was when he said, "Doctor, I could tell that you were worried about that accident. But there isn't any reason to be worried about things like that." (Moody and Perry, 1988, p. 172)

It should be noted that these impressions were formed when the patient was under anesthesia and his eyes were closed.

As illustrated by this account, extrasensory perceptions are present in after-death narratives, just as they are in prenatal accounts. Sabom (1982) reported the case of a soldier who had been severely injured by an explosion. The blast burned his eyes, blinding him for weeks, yet this man described detailed visual images of the battlefield and the operating table, and later identified the surgeon's voice from having heard it during surgery, although both his eardrums had been perforated by the explosion. Such accounts clearly defy traditional physical explanations. 
Although the origins of many phenomenological aspects of NDEs are hotly disputed, most of the arguments have centered on the "otherworldly" portions of the experience, such as the "tunnel" or transition sensation and the emergence into a radiant world peopled with various beings, which cannot be independently verified. Conventional medical explanations attribute near-death visions to hallucinogenic effects of disease conditions, drugs, or chemical changes in the dying brain (Broughton, 1991; Milbourne, 1979; Rodabough, 1985; Siegel, 1977). Yet NDEs occur in the absence of disease and drugs, as in death by trauma, and no consistent match has been found between medications, anesthetics, hallucinogens, street drugs, blood-gas levels, acid-base balance disturbances, or pathology and the NDE (Morse and Perry, 1990; Zaleski, 1987). Arguments and counterarguments abound for dismissing or validating the reality of near-death phenomena, but to date none are conclusive. Only those arguments that specifically address the out-of-body-but-in-this-reality phase of the near-death experience are treated here as a way of illustrating the difficulties in using traditional medical models to account for the data. Veridical out-of-body experiences challenge traditional explanations in the same ways prenatal phenomena do: the cellular sources of memory are presumed to be nonfunctional. The only difference is that near-death reductionists focus on the central nervous system rather than other tissues.

Autoscopic hallucinations have been have been put forth to explain some of the out-of-body phenomena associated with NDEs (Alcock, 1981; Mitchell, 1981), but strong counterarguments confute this position (Moody, 1975; Morse and Perry, 1990). Autoscopic hallucinations, which occur to about 2 percent of the population and are associated with brain tumors, strokes, and migraine headaches, consist of seeing a mirror-image of the self, frequently only from the shoulders up, dressed the same way as the subject, and often mimicking the movements the subject makes. The hallucinated self-image may be superimposed on reality or exist in a hallucinatory setting. But these images are seen from the vantage point of the subject's physical eyes. By contrast, in the NDE, the deceased's vantage point is outside his or her body and at some distance from it, looking at reality. The remarkable lucidity, and the rational and detailed recall of NDE reports hardly resemble the confusion and distortion of most hallucinatory medical and psychological conditions.

Autoscopic hallucinations are related to other forms of depersonalization, a psychic defense with adaptive merit for the survival of 
the ego. Depersonalization, which refers to the sense of separation of the self from events happening to the body, was first advanced to explain NDEs by Russell Noyes and Roy Kletti (Noyes, 1980, 1981, 1982-83; Noyes and Kletti, 1972), who based their work on earlier psychoanalytical arguments by Oskar Pfister (1930) and R. C. A. Hunter (1967). According to Noyes, the out-of-body experiences and other dynamics in NDEs have an adaptive function in permitting the frightened, threatened ego to avoid knowledge of its demise. Yet Noyes himself found it difficult to equate the expansiveness, lucidity, joy, assurance, and better-than-normal well-being of NDEs with the clinical characteristics of depersonalization, including emotional detachment from the body; loss of meaning, intensity and emotion; distortion of time; and the sensation that one's own thought processes seem strange and unreal. The two states share a degree of detachment, but depersonalization diminishes experience while NDEs enhance it.

Noyes' research was based on the accounts of people facing what they believed was certain death, mostly records of extended lifethreatening ordeals, such as mountain-climbing and life-boat journals, and not on accounts of resuscitated victims of clinical death (Noyes, 1980, 1981, 1982-83; Noyes and Kletti, 1972). This demographic distinction is significant, because Noyes stated that belief in imminent death is sufficient to trigger an NDE. Later research refuted this (Greyson, 1990; Morse and Perry, 1990). Melvin Morse showed that a life-threatening illness is insufficient to cause NDEs; he postulated that hallucinations of detachment may be a prelude to the NDE, but that the NDE only begins at "death proper."

Other researchers have stressed that out-of-body experiences resemble the depersonalization experiences found in dissociative disorders, such as the splitting during trauma or the onset of multiple personality disorder (for example, Serdahely, 1992). In such cases, the person's awareness seems to detach itself from the body, viewing events from above, although independent verification of a true outof-body vantage point is not part of these records. The separate sensation may be only wishful thinking. Moreover, a large number of these accounts involve fantasy experiences or other distractions to draw the individual's attention away from the painful events going forward (Ross, 1989). The dissociative states of some syndromes are clearly experienced as being unreal, of feeling "as if," quite unlike the hyperreality of the NDE out-of-body experience (American Psychiatric Association, 1994). Furthermore, people diagnosed with dis- 
sociative disorders are not necessarily reliable reporters of their experience. Their condition involves significant memory loss, and, as a group, they exhibit a higher level of suggestibility and hypnotizability than the normal population. To date, the research suggests only a tenuous relationship between dissociative disorders and NDEs.

One of the weightier arguments, originally based on Wilder Penfield's reports of electrical stimulation to certain brain sites, postulates that anatomical structures associated with the Sylvian fissure of the right temporal lobe create certain near-death phenomena (Morse, Venecia, and Milstein, 1989; Saavedra-Aguilar and GómezJeria, 1989). Champions of the right temporal lobe, including Morse, who is hardly skeptical of NDEs, have employed a wide variety of techniques, including psychoactive drugs, oxygen deprivation, and epileptic seizures, to create altered states resembling NDEs, including the sensation of leaving the body. But the findings deserve qualification.

First, these arguments rely on the unsubstantiated assumption that the right temporal lobe somehow continues to function after other measurable brain activity has ceased. In other words, it is somehow supposed to be virtually the last part of the brain to die. Second, the experimental results come from live patients producing measurable brain waves under conditions that may or may not resemble what occurs at death. Saying that the Sylvian fissure is capable of producing certain percepts under special conditions during life is very different from assuming that that part of the brain dominates consciousness after death and that it functions in the same manner. Many NDE survivors have no measurable brain activity, often for an extended period of time. The gross alterations in consciousness represented by the merest variation in the frequency and amplitude of brain waves suggest that the cessation of all measurable EEG activity should have a dramatic effect. There is no way to know whether this effect would resemble what occurs in any state of measurable activity.

Third, the entire argument is based on Penfield's findings regarding the artificial activation of anatomical structures, yet Penfield (1975) stated clearly that his electrical stimulation of the brain created sensations that were not perceived as real, but "as if." Subjects did not sense themselves participating in the activities they were envisioning, but were aware of two streams of experience: one in the surgical room and a second they were seeing, which was usually the memory of a real past event, not a totally new experience. They re- 
ported that the memories felt artificial, mechanical and forced. Paul MacLean (1990) cautioned that this kind of artificial stimulation creates equally artificial responses that are unlikely to match real-life experience. In contrast, people who experience NDEs say they are "more real" than material life.

And finally, the veridical out-of-body experiences clearly are not hallucinations, that is, purely mental events such as the ones created by Sylvian fissure stimulation, because something really does leave the body after death. Verified reports, such as the ones presented here, are technically impossible as eyewitness accounts in the literal sense, either because the subject's eyes are closed or damaged, or because the events described are not within the visual field of the subject's body. These verified reports are not hallucinations. To cite one more example of verified remote viewing, in two independent cases at different locations, survivors found their consciousness had drifted up to the roof tops of the hospitals where their bodies were being resuscitated (Ring and Lawrence, 1993). And, in as odd a coincidence as imaginable, both people just happened to see abandoned shoes on those roofs. Their detailed descriptions of the shoes and their locations were independently verified by people who had to climb out onto the roofs because the shoes were not otherwise visible.

To summarize all of the above, none of the psychologically or physiologically based arguments holds up well for the out-of-body phase of near-death phenomena, primarily because they are conclusions extrapolated from research on other states: their parallels with neardeath conditions are tenuous at best; and none explains all the data. Neither nonlocal nor local theories for the source of consciousness can account for out-of-body phenomena. To date, traditional medical explanations for the out-of-body portion of near-death experiences must be considered as speculative and inconclusive as the more radical notion that some as-yet-unexplained physically transcendent dynamic is at work.

Nevertheless, the evidentiary aggregate lends weight to the view that something extraordinary is going on during the prenatal and postmortem periods of the life span. Pre-birth and after-death outof-body consciousness appear to share a relative independence from the body and brain. Their psychology is remarkably similar, though they differ in the apparently greater ability of the near-death consciousness to move to locations remote from the body and to transmit messages or sensory impressions to the living, and the absence of a co-conscious source in the body. Except for the last, these capabilities 
may, in fact, be shared by the transcendent source of prenatal consciousness, though this correlation awaits further research. The noetic parallels between these two states are shown in Table 1.

The similarities between these two states are striking. While it could be argued that much of the prenatal data reflects the phe-

\section{Table 1}

\section{Comparison of Pre-Birth and Post-Death Consciousness}

\begin{tabular}{|c|c|c|}
\hline & Pre-Birth & Post-Death \\
\hline Attitude toward life: & $\begin{array}{l}\text { Necessary but } \\
\text { unpleasant } \\
\text { Obligation to } \\
\text { be born incarnate }\end{array}$ & $\begin{array}{l}\text { Necessary; not as } \\
\text { pleasant as the } \\
\text { spiritual realm } \\
\text { Obligation to return } \\
\text { to incarnate life }\end{array}$ \\
\hline Self boundaries: & $\begin{array}{l}\text { Real, but not } \\
\text { physical except as } \\
\text { related to fetal body } \\
\text { Transcendent self has } \\
\text { no body but is } \\
\text { spatially located in, } \\
\text { and limited to, an } \\
\text { area around the } \\
\text { mother's body } \\
\text { Includes fetal body, } \\
\text { sometimes viewed as } \\
\text { alien }\end{array}$ & $\begin{array}{l}\text { Real, but not } \\
\text { physical in the } \\
\text { ordinary sense } \\
\text { Transcendent self is } \\
\text { not substantial; form } \\
\text { fits expectations. } \\
\text { Located for a period } \\
\text { limited to vicinity of } \\
\text { body, loved ones, or } \\
\text { places the subject } \\
\text { wishes to "visit" } \\
\text { Includes dead body, } \\
\text { now regarded as } \\
\text { alien and coarse }\end{array}$ \\
\hline Perception of temporality: & Timeless present & $\begin{array}{l}\text { Timeless present } \\
\text { Some time distortion }\end{array}$ \\
\hline Concept of other: & $\begin{array}{l}\text { Fully mature } \\
\text { Insightful, telepathic } \\
\text { knowledge of others' } \\
\text { minds; compassionate } \\
\text { Records and } \\
\text { processes information } \\
\text { without emotional } \\
\text { loading or neurotic } \\
\text { projection }\end{array}$ & $\begin{array}{l}\text { Fully mature } \\
\text { Insightful, telepathic } \\
\text { knowledge of others' } \\
\text { minds; compassionate } \\
\text { Records and } \\
\text { processes information } \\
\text { without emotional } \\
\text { loading or neurotic } \\
\text { projection }\end{array}$ \\
\hline
\end{tabular}


Table 1

Continued

\begin{tabular}{|c|c|c|}
\hline & Pre-Birth & Post-Death \\
\hline Locus of control: & External & External \\
\hline Level of abstraction: & $\begin{array}{l}\text { Spatiotemporal } \\
\text { boundaries appear to } \\
\text { be Newtonian, but } \\
\text { the source of } \\
\text { consciousness can } \\
\text { operate outside some } \\
\text { physical boundaries }\end{array}$ & $\begin{array}{l}\text { Spatiotemporal } \\
\text { boundaries appear to } \\
\text { be Newtonian, but } \\
\text { the source of } \\
\text { consciousness can } \\
\text { operate outside some } \\
\text { physical boundaries }\end{array}$ \\
\hline Options for action: & Be born or self-abort & Return to life or die \\
\hline Correct action: & $\begin{array}{l}\text { Be born despite pain } \\
\text { and repugnance }\end{array}$ & Return to life \\
\hline
\end{tabular}

nomenology of the altered states that produced the material, that is relevant only for adult regression accounts, but not for the spontaneous reports by children, and this argument does not hold up for the near-death memories, which are obtained from adults in normal states. Arguments that fetal awareness is conditioned at the cellular level by the mother's physiology cannot account for near-death experiences. And the arguments advanced to account for the mature, egocentric neurological and psychological decay of the NDEs have no counterpart in fetal awareness, according to developmental psychology and anatomy. The traditional positions are inadequate to account for the data, and in the aggregate, the findings suggest that some unknown source of awareness transcends the physical limits of the body, as currently understood, at the extremes of human life.

\section{References}

Achterberg, J. (1985). Imagery in healing: Shamanism and modern medicine. Boston, MA: Shambhala.

Achterberg, J. (1994). Healing images and symbols in nonordinary states of consciousness. ReVision 16(4), 148-156. 
Alcock, J. E. (1981). Psychology and near-death experiences. In K. Frazier (Ed.), Paranormal borderlands of science (pp. 153-169). Buffalo, NY: Franklin Book Co.

American Psychiatric Association. (1994). Diagnostic and statistical manual of mental disorders (4th ed.). Washington, DC: American Psychiatric Press.

Anand, K. J. S., and Hickey, P. R. (1987). Pain and its effects in the human neonate and fetus. New England Journal of Medicine, 317(21), 1321-1329.

Baden, M. M., and Hennessee, J. A. (1989). Unnatural death: Confessions of a medical examiner. New York, NY: Random House.

Blackmore, S. J. (1993). Near-death experiences in India: They have tunnels too. Journal of Near-Death Studies, 11, 205-218.

Bloom, F. E., Lazerson, A., and Hofstadter, L. (1985). Brain, mind, and behavior. New York, NY: Freeman.

Blum, T. (Ed.). (1993). Prenatal perception, learning and bonding. Seattle, WA: Leonardo.

Bower, T. G. R. (1977). Primer of infant development. San Francisco, CA: Freeman.

Broughton, R. S. (1991). Parapsychology: The controversial science. New York, NY: Ballantine.

Buchheimer, A. (1987). Memory-Preverbal and verbal. In T. R. Verny (Ed.). Pre-and perinatal psychology: An introduction. (pp. 52-66). New York, NY: Human Sciences Press.

Carr, C. (1993). Death and near death: A comparison of Tibetan and Euro-American experiences. Journal of Transpersonal Psychology, 25, 59-110.

Chamberlain, D. B. (1981). Birth recall in hypnosis. Birth Psychology Bulletin, 2(2), 14-18.

Chamberlain, D. B. (1987). Consciousness at birth: The range of empirical evidence. In T. R. Verny (Ed.), Pre- and perinatal psychology: An introduction (pp. 69-90). New York, NY: Human Sciences Press.

Chamberlain, D. B. (1988a). Babies remember birth: And other extraordinary scientific discoveries about the mind and personality of your newborn. Los Angeles. CA: Tarcher.

Chamberlain, D. B. (1988b). The mind of the newborn: Increasing evidence of competence. In P. Fedor-Freybergh and M. L. V. Vogel (Eds.), Prenatal and perinatal psychology and medicine: Encounter with the unborn, a comprehensive survey of research and practice (pp. 5-22). Park Ridge, NJ: Parthenon.

Chamberlain, D. B. (1990). The expanding boundaries of memory. Pre-and Peri-Natal Psychology Journal, 4(3), 171-189.

Cheek, D. B. (1974). Sequential head and shoulder movements appearing with age regression in hypnosis to birth. American Journal of Clinical Hypnosis, 16, 261-266.

Cheek, D. B. (1975). Maladjustment patterns apparently related to imprinting at birth. American Journal of Clinical Hypnosis, 18, 75-82.

Cheek, D. B. (1986). Prenatal and perinatal imprints: Apparent prenatal consciousness as revealed by hypnosis. Pre- and Peri-Natal Psychology Journal, 1(2), 97-110.

Cheek, D. B. (1992). Are telepathy, clairvoyance and "hearing" possible in utero? Suggestive evidence as revealed during hypnotic age-regression studies of prenatal memory. Pre- and Peri-Natal Psychology Journal, 7(2), 125-137.

Dennett, D. (1991). Consciousness explained. Boston, MA: Little, Brown.

Dossey, L. (1989). Where in the world is the mind? Advances, 6(3), 38-47.

Eccles, J. C. (1989) Evolution of the brain: Creation of the self. London, England: Routledge.

Flavell, J. H. (1985). Cognitive development (2nd ed.). Englewood Cliffs, NJ: PrenticeHall.

Gabriel, M., and Gabriel, M. (1992). Voices from the womb. Lower Lake, CA: Aslan. Galluscio, E. H. (1990). Biological psychology. New York, NY: Macmillan. 
Greenough, W. T. (1987). Experience effects on the developing and mature brain: Dendritic branching and synaptogenesis. In N. A. Krasnegor, E. M. Blass, M. A. Hofer, and W. P. Smotherman (Eds.), Perinatal development: A psychological perspective (pp. 195-221). New York, NY: Academic Press.

Gregory, R. L. (Ed.). (1987). The Oxford companion to the mind. New York, NY: Oxford University Press.

Greyson, B. (1985). A typology of near-death experiences. American Journal of Psychiatry, 142, 967-969.

Greyson, B. (1990). Near-death encounters with and without near-death experiences: Comparative NDE scale profiles. Journal of Near-Death Studies, 8, 151-161.

Grof, S. (1985). Beyond the brain: Birth, death and transcendence in psychotherapy. Albany, NY: State University of New York Press.

Grof, S., and Bennett, H. Z. (1990). The holotropic mind: The three levels of human consciousness and how they shape our lives. San Francisco, CA: HarperSanFrancisco.

Hunter, R. C. A. (1967). On the experience of nearly dying. American Journal of Psychiatry, 124, 122-125.

Janov, A. (1970). The primal scream. New York, NY: Delta.

Janov, A. (1983). Imprints: The lifelong effects of the birth experience. New York, NY: Coward-McCann.

Josephson, B., and Pallikari-Viras, F. (1991). Biological utilization of quantum nonlocality. Foundations of Physics, 21, 197-207.

Laing, R. D. (1982). The voice of experience. New York, NY: Pantheon.

Lieberman, M. (1963). Early developmental stress and later behavior. Science, 141, 824.

Longman, A. J., Lindstrom, B., and Clark, M. (1988). Sensory-perceptual experiences of bereaved individuals: Additional cues for survivors. American Journal of Hospice Care, 5(4), 42-45.

MacLean, P. D., and. Rosenfeld, A. H. (1976). The archaeology of affect. (U.S. Government Document 017-024-00549-5).

MacLean, P. D. (1990). The triune brain in evolution: Role in paleocerebral functions. New York, NY: Plenum.

Milbourne, C. (1979). Search for the soul: An insider's report on the continuing quest by psychics and scientists for evidence of life after death. New York, NY: Crowell.

Mitchell, J. L. (1981). Out-of-body experiences: A handbook. Jefferson, NC: McFarland.

Moody, R. A. (1975). Life after life. Covington, GA: Mockingbird.

Moody, R. A. (1977). Reflections on life after life. St. Simon's Island, GA: Mockingbird.

Moody, R. A., and Perry, P. (1988). The light beyond. New York, NY: Bantam.

Morse, M., and Perry, P. (1990). Closer to the light: Learning from the near-death experiences of children. New York, NY: Villard.

Morse, M., and Perry, P. (1992). Transformed by the light: The powerful effect of neardeath experiences on people's lives. New York, NY: Villard.

Morse, M. L., Venecia, D., and Milstein, J. (1989). Near-death experiences: A neurophysiological explanatory model. Journal of Near-Death Studies, 8, 45-53.

Noyes, R. J. (1980). Attitude change following near-death experiences. Psychiatry 43, 234-242.

Noyes, R. J. (1981). The encounter with life-threatening danger: Its nature and impact. Essence, 5, 21-32.

Noyes, R. J. (1982-3). The human experience of death or, what can we learn from near-death experiences? Omega, 13, 251-259.

Noyes, R., and Kletti, R. (1972). The experience of dying from falls. Omega, 3, 45-52.

Penfield, W. (1975). The mystery of the mind: A critical study of consciousness and the human brain. Princeton, NJ: Princeton University Press.

Pert, C., Ruff, M., Weber, R. J., and Herkenham, M. (1985). Neuropeptides and their receptors: A psychosomatic network. Journal of Immunology, 135, 820s-826s. 
Pfister, O. (1930). Shockdenken und Shockphantasien bei höchster Todesgefahr. International Zeitschrift für Psychoanalyse, 16, 430-455.

Pribram, K. H. (1971). Languages of the brain: Experimental paradoxes and principles in neuropsychology. Englewood Cliffs, NJ: Prentice-Hall.

Pribram, K H. (1991). Brain and perception: Holonomy and structure in figural processing. Hillsdale, NJ: Lawrence Erlbaum Associates.

Raikov, V. L. (1980). Age regression to infancy by adult subjects in deep hypnosis. American Journal of Clinical Hypnosis, 22, 156-163.

Radin, D., and Nelson, R. (1989). Evidence of consciousness-related anomalies in random physical systems. Foundations of Physics, 19, 1499-1514.

Restak, R. M. (1979). The brain: The last frontier. Garden City, NY: Doubleday.

Restak, R. M. (1984). The brain. New York, NY: Bantam.

Restak, R. M. (1986). The infant mind. New York, NY: Doubleday.

Ring, $K$ (1980). Life at death: $A$ scientific investigation of the near-death experience. New York, NY: Coward, McCann and Geoghegan.

Ring, K. (1984). Heading toward omega: In search of the meaning of the near-death experience. New York, NY: Morrow.

Ring, K, and Lawrence, M. (1993). Further evidence for veridical perception during near-death experiences. Journal of Near-Death Studies, 11, 223-230.

Rodabough, T. (1985) NDEs: Examination of the supporting data and alternative explanations. Death Studies, 9, 95-113.

Ross, C. (1989). Multiple personality disorder: Diagnosis, clinical features, and treatment. New York, NY: Wiley.

Rossi, E. L. (1990). From mind to molecule: More than a metaphor. In J. K. Zeig, and S. Gilligan (Eds.), Myths, methods, and metaphors (pp. 445-472). New York, NY: Brunner/Mazel.

Saavedra-Aguilar, J., and Grómez-Jeria, J. (1989). A neurobiological model for neardeath experiences. Journal of Near-Death Studies, 7, 205-222.

Sabom, M. (1982). Recollections of death: A medical investigation. New York, NY: Harper and Row.

Serdahely, W. J. (1992). Similarities between near-death experiences and multiple personality disorder. Journal of Near-Death Studies 11, 19-38.

Siegel, R. K (1977, October). Hallucinations. Scientific American, pp. 53-78.

Siegel, R. K (1980). The psychology of life after death. American Psychologist, 35, 911-931.

Spehlmann, R. (1981). EEG primer. New York, NY: Elsevier.

Tart, C. T. (Ed.). (1972). Altered states of consciousness. Garden City, NY: Doubleday/Anchor.

Tart, C. T. (1983). States of consciousness. El Cerrito, CA: Psychological Processes.

TenDam, H. (1990). Exploring reincarnation. London, England: Penguin.

Tomatis, A. A (1987). Ontogenesis of the faculty of listening. In T. R. Verny (Ed.), Pre- and perinatal psychology: An introduction (pp. 23-35). New York, NY: Human Sciences Press.

Tronick, E., and Adamson, L. (1980). Babies as people: New findings on our social beginnings. New York, NY: Collier.

Van Husen, J. E. (1988). The development of fears, phobias and restrictive patterns of adaptation following attempted abortions. Pre-and Peri-natal Psychology Journal, 2(3), 179-185.

Veldman, F. (1982, November 11). Life welcomed and affirmed. The St. Cloud Visitor, Newspaper of the Catholic Diocese of St. Cloud, Minnesota, Vol. LXXI.

Verny, T., and Kelly, J. (1982). The secret life of the unborn child. New York, NY: Delacorte.

Wambach, H. (1981). Life before life. New York, NY: Bantam. (Original work published 1979) 
Wade, J. (1996). Changes of mind: A holonomic theory of the evolution of consciousness. Albany, NY: State University of New York Press.

Whitton, J. L., and Fisher, J. (1986). Life between life. New York, NY: Warner.

Zaleski, C. (1987). Otherworld journeys: Accounts of near-death experience in medieval and modern times. New York, NY: Oxford University Press. 